The role of competitive counterion adsorption on the electrolyte induced surface ordering in methyl ester sulfonate surfactants at the air-water interface

Hui Xu, Peixun Li, Kun Ma, Rebecca J L Welbourn, Jeffrey Penfold, Robert K Thomas, David W Roberts, Jordan T Petkov.

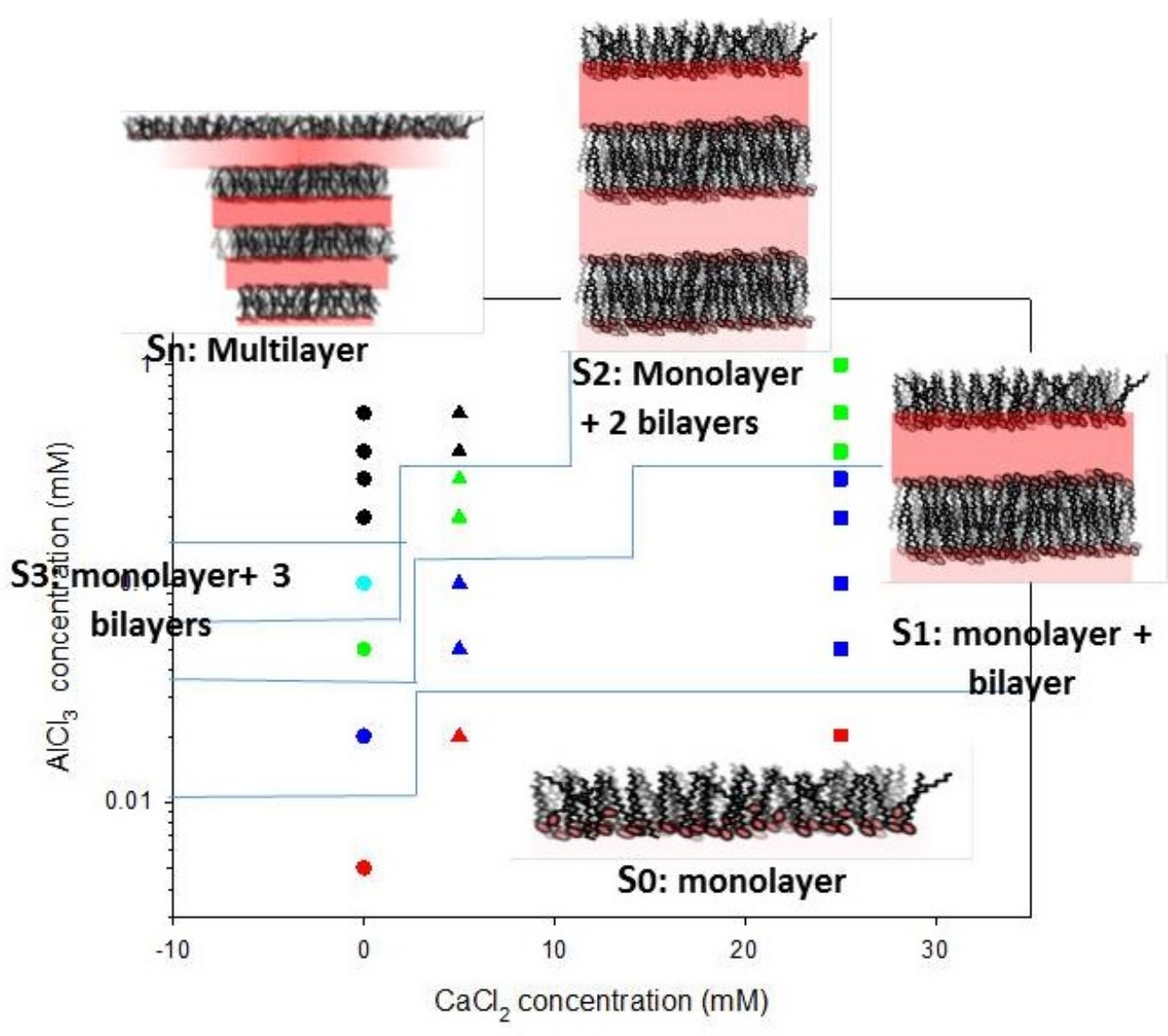




\title{
The role of competitive counterion adsorption on the electrolyte induced surface ordering in methyl ester sulfonate surfactants at the air- water interface
}

\author{
Hui $\mathrm{Xu}^{1}$, Peixun $\mathrm{Li}^{2}$, Kun $\mathrm{Ma}^{2}$, Rebecca J L Welbourn ${ }^{2}$, Jeffrey Penfold ${ }^{2,3}$, \\ Robert K Thomas ${ }^{3}$, David W Roberts ${ }^{4}$, Jordan T Petkov ${ }^{5}$.
}

1. KLK Oleo, SDN BHD, Menara KLK, Muliara Damansara, 47810, Petaling, Jaya Selanger, Malaysia

2. ISIS Facility, Rutherford Appleton Laboratory, STFC, Chilton, Didcot, OXON, OX11 0QX, UK

3. Physical and Theoretical Chemistry Laboratory, Oxford University, South Parks Road, Oxford, OX1 3QZ, UK

4. School of Pharmacy and Biomolecular Sciences, Liverpool John Moores University, Liverpool, L3 3AF, UK

5. Lonza UK, GB-Blackley, Manchester, Lancs, M9 8ES, UK

Corresponding author: Jeffrey Penfold, jeff.penfold@stfc.ac.uk

Keywords: Methyl ester sulfonate surfactants, adsorption at air-water interface, surface multilayers, competitive counterion adsorption 


\begin{abstract}
The strong binding of $\mathrm{Al}^{3+}$ trivalent counterions to the anionic surfactants sodium polyethylene glycol monoalkyl ether sulfate and $\alpha$-methyl ester sulfonate results in surface multilayer formation at the air-water interface. In contrast the divalent and monovalent counterions $\mathrm{Ca}^{2+}$ and $\mathrm{Na}^{+}$result only in monolayer adsorption. Competitive counterion adsorption has been extensively studied in the context of surfactant precipitation and re-dissolution, but remains an important feature in understanding this surface ordering and how it can be manipulated.
\end{abstract}

The $\alpha$-methyl ester sulfonate surfactants are a promising class of anionic surfactants which have much potential for improved performance in many applications, greater tolerance to extreme solvent conditions such as water hardness, biocompatibility and sustainable production. Hence in this study we have used neutron reflectivity to extend previous studies on the surface ordering of the $\alpha$-methyl ester sulfonate surfactant, sodium tetradecanoic 2-sulfo 1methyl ester, in the presence of electrolyte to investigate the role of binary mixtures of electrolytes, $\mathrm{AlCl}_{3} / \mathrm{CaCl}_{2}$, and $\mathrm{AlCl}_{3} / \mathrm{MgCl}_{2}$.

In the mixed electrolytes the evolution of the surface structure, from monolayer to multilayer with increasing $\mathrm{AlCl}_{3}$ concentration, is observed. It is broadly similar to that reported for the addition of only $\mathrm{AlCl}_{3}$. However with increasing $\mathrm{CaCl}_{2}$ concentration the structural evolution is shifted progressively to higher $\mathrm{AlCl}_{3}$ concentrations. Similar observations occur for the $\mathrm{AlCl}_{3}$ $/ \mathrm{MgCl}_{2}$ mixtures. However the presence of the $\mathrm{MgCl}_{2}$ results in an additional phenomenon; the partial co-adsorption of a more compact lamellar structure which exists until the highest $\mathrm{AlCl}_{3}$ concentrations. The results demonstrate the importance of the competitive adsorption of different counterions in driving and controlling the formation of surface multilayer structures with anionic surfactants. Furthermore it offers a facile route to the manipulation of these surface structures. 


\section{INTRODUCTION}

The structure and function of anionic surfactants, the major ingredient in many household formulations, have evolved to meet the increasing demands for improved performance $(1,2)$. The development of the alkyl benzene sulfonates, LAS, and alkyl ethoxy ether sulfate, SLES, surfactants has led to improved hard water characteristics, improved detergency, enhanced low temperature performance and improved biocompatibility and biodegradability $(1,2)$. The desire for further improvements and the developing need for production from sustainable sources has identified the $\alpha$-methyl ester sulfonate, MES, anionic surfactants as an increasingly attractive option. The MES surfactants are synthesised from renewable palm oil sources and are increasingly seen as a viable alternative to the petroleum derived counterparts (3-8). Hence the synthesis and purification of MES have been extensively studied $(6,7,9)$, and their basic physicochemical properties and aspects of their surface adsorption and self-assembly have been studied (9-12). Improved hard water tolerance, greater biodegradability and better cold water detergency have been demonstrated with the MES surfactants (13-17).

Recently Xu et al (18) described a new laboratory synthesis of MES, based on the direct sulfonation of the methyl ester by $\mathrm{SO}_{3}$ introduced from the vapour phase. This enabled the use of neutron reflectivity and surface tension to more definitively characterise the surface adsorption, using purer and better defined samples than previously possible. Subsequently $\mathrm{Xu}$ et al $(19,20)$ have demonstrated the ability of MES to form surface multilayer structures with the addition of $\mathrm{AlCl}_{3}$, and characterise the nature of surface and micelle mixing in the eutectic mixture of the $\mathrm{C}_{16^{-}}$and $\mathrm{C}_{18}$-MES surfactants. Surface multilayer formation has also been extensively demonstrated with LAS and SLES for the addition of multivalent counterions. The strong binding of $\mathrm{Ca}^{2+}$ to LAS promoted surface multilayer formation (21), and for SLES with the addition of $\mathrm{Al}^{3+}(22-24)$. The strong counterion binding promotes the attractive interaction which results in the adsorption / formation of a concentrated lamellar structure at the interface from the dilute solution. It occurs in these systems in which the nature of the anionic surfactant structure promotes improved solubility and a degree of tolerance to precipitation in the presence of multivalent counterions. Important aspects that have only been briefly explored are counterion specific effects, the role of hydration, and the competitive adsorption between counterions. Xu et al (25) explored ion specific effects by exploring the impact of a range of different trivalent counterions on the surface ordering of SLES. The evolution in the surface ordering depended upon the nature of the counterion, its hydrated radius and its strength of binding. 
The impact of monovalent electrolytes on anionic surfactant adsorption and self-assembly is well established, resulting in enhanced adsorption (26), reduction in critical micelle concentrations, cmc, (27) and in micellar growth (28). The impact of multivalent counterions, divalent and trivalent ions such as $\mathrm{Ca}^{2+}, \mathrm{Mg}^{2+}$ and $\mathrm{Al}^{3+}$, is more significant. The strong binding and complexation leads rapidly to precipitation in many cases. This has been extensively studied in the context of water hardness and the phenomena of precipitation and re-dissolution have been extensively reported (29-32). It was observed that the addition of $\mathrm{NaCl}$ increases the concentration of $\mathrm{Ca}^{2+}$ required to promote precipitation $(32,33)$; where the addition of $\mathrm{NaCl}$ reduces cmc values and the associated monomer concentrations. Furthermore this is aided by the competition between $\mathrm{Na}^{+}$and $\mathrm{Ca}^{2+}$ to bind to micelles and the surface. It was observed that $\mathrm{Ca}^{2+}$ binds preferentially, but that the binding decreases as the $\mathrm{Na}^{+} / \mathrm{Ca}^{2+}$ ratio increases. Competitive adsorption of multivalent metal ions and their role in flocculation is important in the environmental removal of heavy metals, such as lead and zinc $(31,34,35)$. Haverd and Warr (36) discussed the role of hydrated ion radius and free energy of hydration on the selective binding of alkali metal ions, and showed an increasing binding strength in the order $\mathrm{Na}^{+}<\mathrm{K}^{+}<\mathrm{Rb}^{+}<\mathrm{Cs}^{+}$. Alargova et al (37-39) explored the impact of $\mathrm{Al}^{3+}$ binding on the micellar growth and surface tension of the alkyloxyethylene sulfate anionic surfactants. They showed how the strong binding or complexation of $\mathrm{Al}^{3+}$ results a significant micellar growth which is correlated with the parameter $\xi$, where $\xi=\left(\mathrm{c}_{\mathrm{t}}-\mathrm{cmc}\right) / \mathrm{z}_{\mathrm{m}} \mathrm{c}_{\mathrm{m}}, \mathrm{c}_{\mathrm{t}}$ is the surfactant concentration, $\mathrm{z}_{\mathrm{m}}$ the counterion charge and $\mathrm{cm}$ the counterion concentration. For $\xi<1$, where the $\mathrm{Al}^{3+}$ charge is in excess, micellar growth occurs. For $\xi>1$, where the anion charge is now in excess, the micelles are small and globular. The binding of $\mathrm{Al}^{3+}$ ions more effectively reduces the interheadgroup repulsion and preferred curvature, and drives the micellar growth. It was observed that the micellar growth is more significant for the trivalent than divalent ions. Significant differences between ions of the same valence were observed and were related to the ion size, hydration and polarizability. For example, the more strongly hydrated $\mathrm{Mg}^{2+}$ was less effective in promoting micellar growth than $\mathrm{Ca}^{2+}$. A simple thermodynamic model, based on the competitive adsorption of $\mathrm{Al}^{3+}$ and $\mathrm{Na}^{+}$between the monolayer and micelle, provided a good description of the associated surface tension behaviour, and provided an estimate of the greater binding energy of $\mathrm{Al}^{3+}$ compared to $\mathrm{Na}^{+}$.

Clearly selective and competitive counterion binding are important factors in determining the extent of precipitation and re-dissolution of anionic surfactants in the presence of electrolyte, micellar growth and interfacial tension. It has already been demonstrated that interesting 
surface properties exist for the MES surfactants in the presence of certain multivalent counterions, and the focus of this study is to explore the extent to which mixed electrolytes determine and control the extent and evolution of the surface ordering encountered in the presence of multivalent counterions. To do this neutron reflectivity measurements have been made at the air - water interface for the $\mathrm{C}_{14}$-MES anionic surfactant in the presence of the mixed electrolytes, $\mathrm{AlCl}_{3} / \mathrm{CaCl}_{2}$, and $\mathrm{AlCl}_{3} / \mathrm{MgCl}_{2}$.

\section{EXPERIMENTAL DETAILS}

The neutron reflectivity, $\mathrm{R}(\mathrm{Q})$, was measured as a function of the wave vector transfer, $\mathrm{Q}$, perpendicular to the surface (where $\mathrm{Q}$ is defined as $\mathrm{Q}=(4 \pi \sin \theta) / \lambda, \theta$ is the grazing angle of incidence, and $\lambda$ the neutron wavelength). The measurements were made on the INTER reflectometer (40) at the ISIS pulsed neutron source in the UK; where the measurements were made at a fixed $\theta$ of $2.3^{\circ}$ and a $\lambda$ range of 1 to $15 \AA$ to cover a $Q$ range of $\sim 0.03$ to $0.3 \AA^{-1}$. The reflectivity was converted to an absolute scale by normalisation to the incident beam intensity and the reflectivity of a $\mathrm{D}_{2} \mathrm{O}$ surface.

The measurements were made in null reflecting water, nrw, $\left(8.8\right.$ mole $\% \mathrm{D}_{2} \mathrm{O} / 91.2$ mole $\%$ $\mathrm{H}_{2} \mathrm{O}$, with a scattering length density, $\rho$, of 0.0 , matched to air), and using deuterium labelled surfactants. The measurements were made in sealed Teflon troughs, with sample volumes $\sim 25$ $\mathrm{mL}$ and at a temperature of $25^{\circ} \mathrm{C}$ Each measurement took $\sim 20$ to 30 mins; measured sequentially on a 7 position sample changer, and repeated $\sim 2-3$ times (for a total lapse time of up to 3 to 6 hours) until the reflectivity profile reached a steady state.

In the kinematic approximation (26) the neutron reflectivity is related to the square of the Fourier Transform of the scattering length density distribution, $\rho(z)$, normal to the surface;

$R(Q)=\frac{16 \pi^{2}}{Q^{2}}\left|\int \rho(z) e^{-i Q z} d z\right|^{2}$

where $\rho(z)=\sum_{i} b_{i} n_{i}(z), n_{i}(z)$ is the number density distribution of species $i$ and $b_{i}$ is the scattering length (the $\sum \mathrm{b}$ values of the different components studied are listed in table 1). As the neutron scattering lengths of $\mathrm{H}$ and $\mathrm{D}$ are quite different $\left(-3.75 \times 10^{-5}\right.$ and $6.67 \times 10^{-5} \AA$ respectively) $\rho(z)$ can be manipulated for organic species by $\mathrm{D} / \mathrm{H}$ isotopic substitution. Hence deuterium labelling enables the reflectivity from different components at the interface to be isolated. This is the basis of the measurements here, as the reflectivity from a deuterium labelled surfactant adsorbed at a null reflecting air-water interface provides a direct estimate of 
the adsorbed amount (26). For monolayer surfactant adsorption the reflectivity is adequately modelled as a single layer of uniform composition using the exact expression for a thin film at the interface (26) to obtain a thickness, $d$, and scattering length density, $\rho$. The adsorbed amount is directly related to the d. $\rho$ product such that the area/molecule, A,

$$
\mathrm{A}=\sum \mathrm{b} / \mathrm{d} \rho
$$

and the adsorbed amount $\Gamma=1 / \mathrm{ANa}$, and $\mathrm{Na}$ is Avogadro's number.

For more complex surface structures the reflectivity is usually modelled using a discreet number of layers, using the optical matrix methods (26), or using a surface multi-bilayer model based on the kinematic approximation $(41,42)$. In modelling the NR data a flat background, typically $\sim 6$ to $8 \times 10^{-6}$, arising from the bulk scattering from the aqueous sub-phase, is included.

Deuterium oxide, $\mathrm{D}_{2} \mathrm{O},(99.9 \%$ purity) was obtained from Sigma Aldrich, and high purity water (resistivity $18.2 \mathrm{M} \Omega \mathrm{cm}$ ) was used throughout. Analytical grade ( $>99.9 \%$ purity) $\mathrm{AlCl}_{3}, \mathrm{NaCl}$ and $\mathrm{CaCl}_{2}$ were used as supplied by Sigma Aldrich. All the glassware, Teflon troughs, spectrophotometer cells used for the NR and SANS measurements and sample preparation were cleaned in alkali detergent (Decon90) and extensively rinsed in ultrapure water.

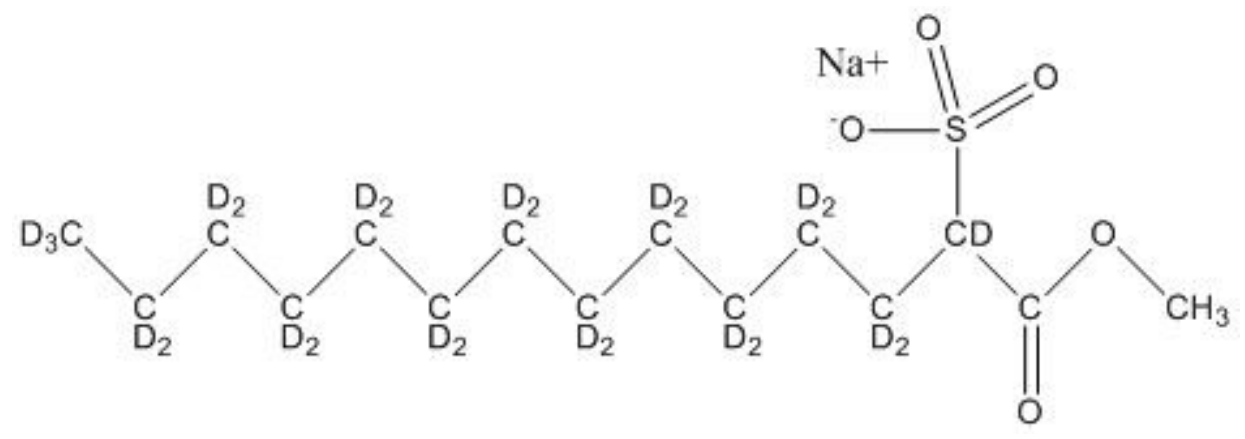

Figure 1. Structure of deuterated MES surfactant.

The sodium alkyl 2-sulfo 1-methyl ester, MES, surfactant was sodium tetradecanoic 2-sulfo 1methyl ester. The form of the MES surfactant used in this study was synthesised with the alkyl chain deuterium labelled, $\left(\mathrm{CD}_{3}\left(\mathrm{CD}_{2}\right)_{11} \mathrm{CD}\left(\mathrm{SO}_{3} \mathrm{Na}\right) \mathrm{COOCH}_{3}\right)$, as shown in figure 1 . It is referred to as $\mathrm{d}_{-} \mathrm{C}_{14}-\mathrm{MES}$, and abbreviated as $\mathrm{C}_{14}$-MES or MES in this paper. The deuterated tetradecanoic methyl ester was produced using perdeuterated tetradecanoic acid and nondeuterated methanol. The surfactant was synthesised by direct sulfonation of the deuterated tetradecanoic methyl ester by $\mathrm{SO}_{3}$ introduced from the vapour phase. Further details of the synthesis and purification are described in detail elsewhere (18). 
The measurements were made at a fixed MES concentration of $1 \mathrm{mM}$ in the presence of $\mathrm{AlCl}_{3}$ $/ \mathrm{CaCl}_{2}$ and $\mathrm{AlCl}_{3} / \mathrm{MgCl}_{2}$ mixed electrolytes. The measurements were made at $\mathrm{CaCl}_{2}$ concentrations of 5 , and $25 \mathrm{mM}$, for $\mathrm{AlCl}_{3}$ concentrations in the range 0.02 to $1.0 \mathrm{mM}$, and in the absence of $\mathrm{AlCl}_{3}$ for $\mathrm{CaCl}_{2}$ concentrations from 0.0 to $100 \mathrm{mM}$. Measurements were also made at $\mathrm{MgCl}_{2}$ concentrations of 5, 10 and $25 \mathrm{mM}$, for $\mathrm{AlCl}_{3}$ concentrations from 0.02 to 0.6 $\mathrm{mM}$, and in the absence of $\mathrm{AlCl}_{3}$ for $\mathrm{MgCl}_{2}$ concentrations from 0.0 to $25 \mathrm{mM}$. A fixed surfactant concentration of $1 \mathrm{mM}$ was selected in order to maximise the electrolyte concentration and composition range to be explored within the finite beam time resources available. Furthermore, for MES and related surfactants (19-25) $1 \mathrm{mM}$ is an ideal surfactant concentration to explore the full range of surface compositions encountered.

\section{RESULTS and DISCUSSION}

\section{(i) $\mathrm{MES} / \mathrm{AlCl}_{3} / \mathrm{CaCl}_{2}$}

The surface adsorption and structure of the adsorbed layer for $1 \mathrm{mM} \mathrm{C}_{14}$-MES were measured using neutron reflectivity in $\mathrm{CaCl}_{2}$, for $\mathrm{CaCl}_{2}$ concentrations up to $50 \mathrm{mM}$; and at a range of fixed $\mathrm{CaCl}_{2}$ concentrations with variable $\mathrm{AlCl}_{3}$ concentrations. The data in the absence of $\mathrm{CaCl}_{2}$ and for $\mathrm{CaCl}_{2}$ concentrations from 5 to $50 \mathrm{mM}$ are all in the form of a monolayer, $\mathrm{S}_{0}$, with a thickness $\sim 20 \pm 2 \AA$, consistent with that previously reported for $\mathrm{C}_{14}$-MES $(18,19)$. The key model parameters are summarised in table S1 in the Supporting Information. Evaluated from equation 1 , using a $\sum \mathrm{b}=2.87 \times 10^{-3} \AA$, the adsorbed amount in the absence of $\mathrm{CaCl}_{2}$ is $2.8 \times 10^{-10} \mathrm{~mol} \mathrm{~cm}^{-2}$ (area/molecule $\sim 60 \AA^{2}$ ), within error the same as reported by Xu et al (18). With the addition of $\mathrm{CaCl}_{2}$, in the range 5 to $50 \mathrm{mM}$, the adsorbed amount has increased to 3.8 x $10^{-10} \mathrm{~mol} \mathrm{~cm}^{-2}$ (area/molecule $\sim 43 \AA^{2}$ ). This compares with previous observations of an adsorbed amount of $3.4 \times 10^{-10} \mathrm{~mol} \mathrm{~cm}^{-2}$ at the cmc, which increased to $3.7 \times 10^{-10} \mathrm{~mol} \mathrm{~cm}^{-2}$ in $0.5 \mathrm{mM} \mathrm{CaCl}_{2}$ and $3.6 \times 10^{-10} \mathrm{~mol} \mathrm{~cm}^{-2}$ in $100 \mathrm{mM} \mathrm{NaCl}$ (18). Hence the increases reported here in $\mathrm{CaCl}_{2}$ are consistent with that previous data; and result from a decrease in the $\mathrm{cmc}$ such that $1 \mathrm{mM} \mathrm{C}_{14}$-MES is closer to the saturated adsorption even in the absence of electrolyte, and due to the impact of the divalent electrolyte. 


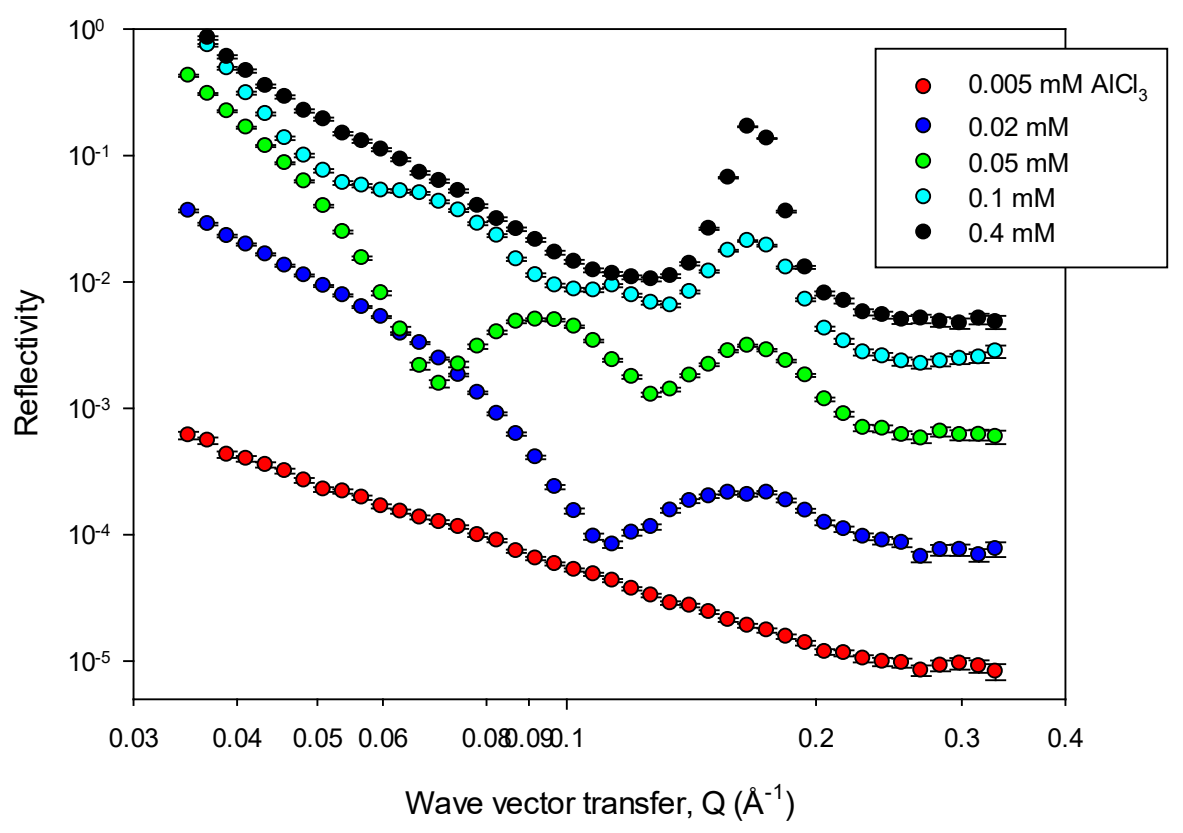

(a)

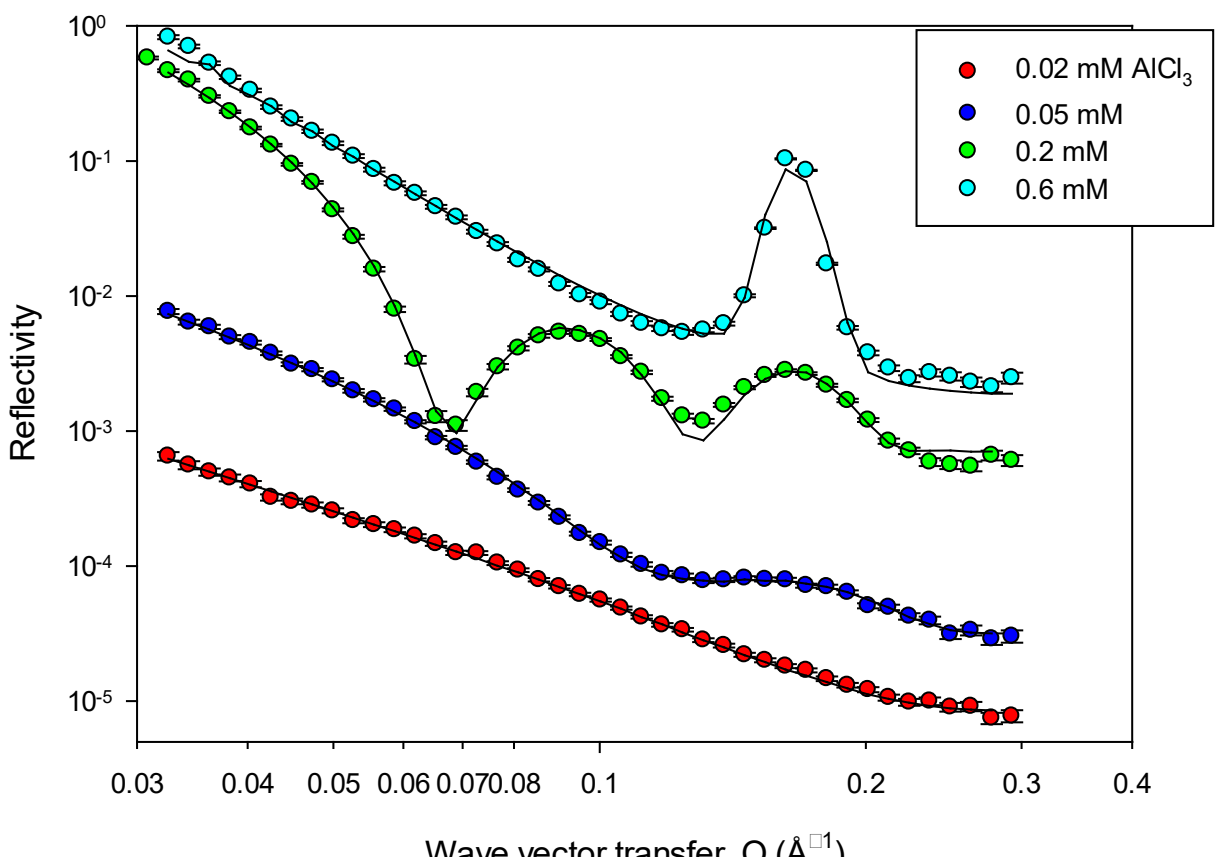

Wave vector transfer, $Q\left(\AA^{\square 1}\right)$

(b) 


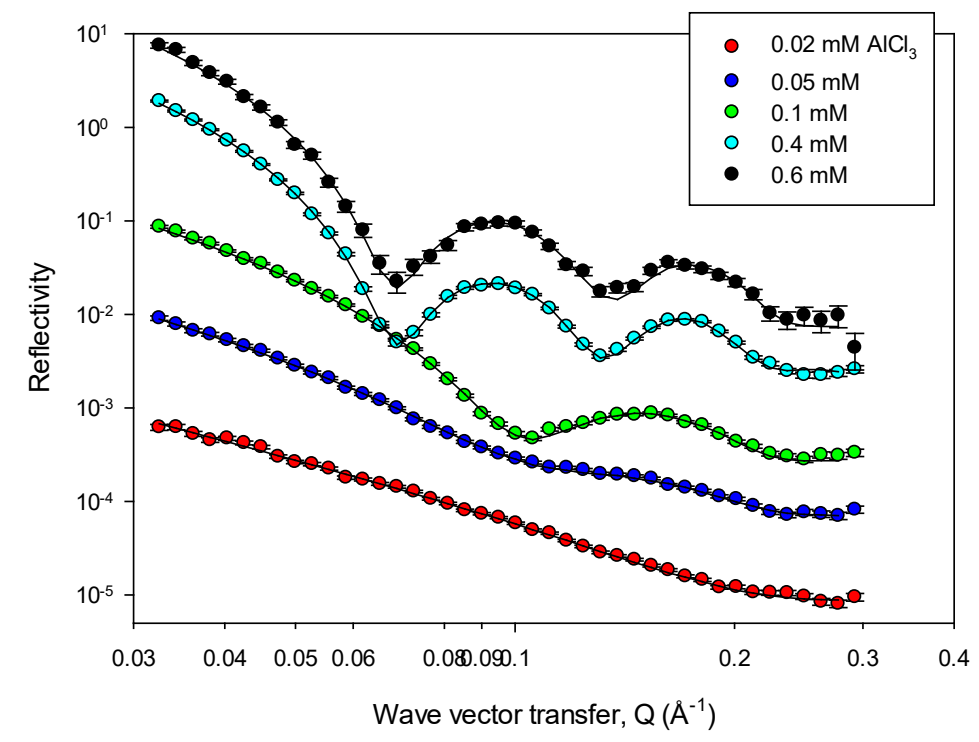

(c)

Figure 2. Neutron reflectivity for $1 \mathrm{mMMES}$ in $\mathrm{AlCl}_{3} / \mathrm{CaCl}_{2}$, (a) no $\mathrm{CaCl}_{2}$, (b) $5 \mathrm{mM} \mathrm{CaCl}$, (c) $25 \mathrm{mM} \mathrm{CaCl}_{2}$; see legend for details. The data in figure la are reproduced from reference 19. Each curve is shifted (from bottom to top) with respect to the previous curve; (a) x16 for $0.02 \mathrm{mM}, x 32$ for $0.05 \mathrm{mM}$ and $x 64$ for 0.1, $0.4 \mathrm{mM}$, (b) $x 4$ for $0.05 \mathrm{mM}, x 32$ for $0.2 \mathrm{mM}$ and x64 for $0.6 \mathrm{mM}$ and (c) $x 8$ for $0.05 \mathrm{mM}$, x32 for $0.1 \mathrm{mM}, x 128$ for $0.4 \mathrm{mM}$ and $x 1024$ for 0.6 $m M$. The solid lines in (b) and (c) are model fits as described in the text and using the key model parameters summarised in table 1 and table S2 in the Supporting Information.

At fixed $\mathrm{CaCl}_{2}$ concentrations $\left(5\right.$, and $25 \mathrm{mM}$ ) and at a range of $\mathrm{AlCl}_{3}$ concentrations (up to 1 $\mathrm{mM}$ ) the surface adsorption evolves from a monolayer to a multilayer structure, as illustrated in figure $2 \mathrm{~b}$ and $\mathrm{c}$ for 5 and $25 \mathrm{mM} \mathrm{CaCl}_{2}$. This is compared with the structural evolution observed with varying $\mathrm{AlCl}_{3}$ concentration in the absence of $\mathrm{CaCl}_{2}$ in figure $2 \mathrm{a}$ (19). In the presence of mixed $\mathrm{AlCl}_{3} / \mathrm{CaCl}_{2}$ electrolyte the evolution in the surface structure is broadly similar to that previously reported in the presence of $\mathrm{AlCl}_{3}$ alone, see figure $2 \mathrm{a}$ (19).

However there are some important differences. At low $\mathrm{AlCl}_{3}$ concentrations the adsorbed layer is still in the form of a monolayer, $\mathrm{S}_{0}$, and has an adsorbed amount $\sim 3.8 \times 10^{-10} \mathrm{~mol} \mathrm{~cm}^{-2}$, similar to that measured in $50 \mathrm{mM} \mathrm{CaCl}_{2}$. The region of monolayer adsorption is extended to increasingly higher $\mathrm{AlCl}_{3}$ concentrations as the $\mathrm{CaCl}_{2}$ concentration increases, up to $0.02 \mathrm{mM}$. 
In contrast, in the absence of $\mathrm{CaCl}_{2}$ it is only a monolayer up to an $\mathrm{AlCl}_{3}$ concentration of 0.005 $\mathrm{mM}$.

In general, as the $\mathrm{AlCl}_{3}$ concentration increases, the nature of the surface adsorption evolves from a monolayer to an ordered layered structure. In the absence of $\mathrm{CaCl}_{2}$ (19) at $\mathrm{AlCl}_{3}$ concentrations of 0.02 to $0.05 \mathrm{mM}$ the reflectivity is in the form of a single interference fringe and then a double interference fringe. These reflectivity profiles are consistent with a single bilayer adsorbed beneath the initial monolayer, $\mathrm{S}_{1}$, and a double bilayer, $\mathrm{S}_{2}$. At an $\mathrm{AlCl}_{3}$ concentration of $0.1 \mathrm{mM}$ three interference fringes are visible and the surface structure corresponds to 3 bilayers, $\mathrm{S}_{3}$. At $\mathrm{AlCl}_{3}$ concentrations of $0.2 \mathrm{mM}$ and higher the reflectivity is characterised by a pronounced Bragg peak at a $\mathrm{Q}$ value $\sim 0.16 \AA^{-1}$, corresponding to a multilayer structure with a large number of bilayers, $>>10$.

In $5 \mathrm{mM} \mathrm{CaCl}_{2}$ the evolution of the surface structure with increasing $\mathrm{AlCl}_{3}$ concentration is broadly similar to that in the absence of $\mathrm{CaCl}_{2}$, except that higher $\mathrm{AlCl}_{3}$ concentrations are required to promote the transitions from monolayer adsorption to the more extended layered surface structures. Whereas at $25 \mathrm{mM} \mathrm{CaCl}_{2}$ only the $\mathrm{S}_{1}$ and $\mathrm{S}_{2}$ structures are observed with increasing $\mathrm{AlCl}_{3}$ concentration.

An approximate surface phase diagram for $1 \mathrm{mM} \mathrm{C} \mathrm{C}_{14} \mathrm{MES}$ in $\mathrm{AlCl}_{3} / \mathrm{CaCl}_{2}$ mixtures, derived from the neutron reflectivity measurements, is shown in figure 3. Although as the $\mathrm{CaCl}_{2}$ concentration increases a broadly similar evolution in the surface structure occurs with increasing $\mathrm{AlCl}_{3}$ concentration, it is shifted to increasingly higher $\mathrm{AlCl}_{3}$ concentrations. At the higher $\mathrm{CaCl}_{2}$ concentrations studied, $25 \mathrm{mM}$, the shift is such that only a more limited range of surface structures are observed. 


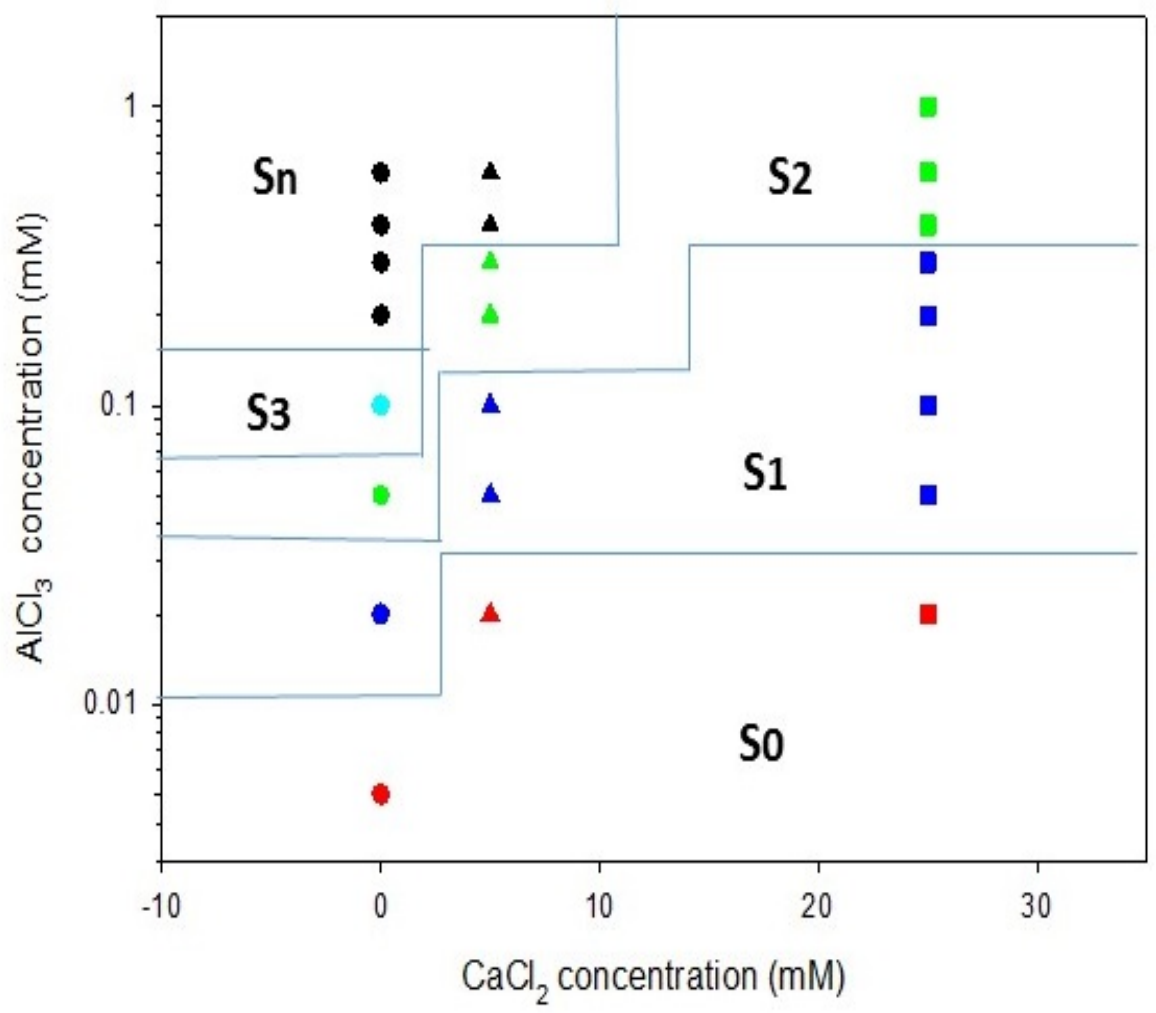

Figure 3. Approximate surface phase diagram for $1 \mathrm{mM} \mathrm{MES} \mathrm{in} \mathrm{AlCl}_{3} / \mathrm{CaCl}_{2}$ mixture, see figure for details. The different data points represent measurements at $0.0 \mathrm{CaCl}_{2}(\bullet), 5 \mathrm{mM}$ $\mathrm{CaCl}_{2}(\mathbf{\Delta})$, and $25 \mathrm{mMCaCl}_{2}(\mathbf{\square})$; and (red) $\mathrm{S}_{0}$ monolayer,(blue) $S_{1}$ monolayer + bilayer, (green) $S_{2} 2$ bilayers, (cyan) $S_{3} 3$ bilayers, and (black) $S_{n}$ multilayers

In detail the surface structures observed in the presence of $\mathrm{CaCl}_{2}$ are similar to those in the absence of $\mathrm{CaCl}_{2}$ (19). In figure $2 \mathrm{~b}$ representative model fits are shown for $1 \mathrm{mM}$ MES in 5 $\mathrm{mM} \mathrm{CaCl}_{2}$ and $0.02,0.05,0.2$ and $0.6 \mathrm{mM} \mathrm{AlCl}_{3}$. The key model parameters are summarised in table 1. 
Table 1. Key model parameters from analysis of neutron reflectivity data for $1 \mathrm{mM} M E S$ / 5 $\mathrm{mM} \mathrm{CaCl}_{2}$ at $\mathrm{AlCl}_{3}$ concentrations of $0.02,0.05,0.2$ and $0.6 \mathrm{mM}$.

\begin{tabular}{|c|c|c|c|c|c|c|c|c|c|c|c|c|}
\hline $\begin{array}{l}\mathrm{AlCl}_{3} \\
\text { concentration } \\
(\mathrm{mM})\end{array}$ & $d_{1}( \pm 1 \AA)$ & $\begin{array}{l}\rho_{1} \\
( \pm 0.05 \\
\mathbf{x} 10^{-6} \\
\left.\AA^{-2}\right)\end{array}$ & $d_{2}$ & $\boldsymbol{\rho}_{2}$ & $d_{3}$ & $\rho_{3}$ & $d_{4}$ & $\rho_{4}$ & d5 & $\rho_{5}$ & $d_{6}$ & $\rho_{6}$ \\
\hline 0.02 & 21 & 3.22 & - & - & - & - & - & - & - & - & - & - \\
\hline 0.05 & 23 & 3.80 & 9 & 0.87 & 17 & 1.93 & - & - & - & - & - & - \\
\hline \multirow[t]{2}{*}{0.20} & 27 & 3.53 & 6 & 1.04 & 25 & 4.18 & 8 & 1.38 & 24 & 4.24 & 16 & 0.60 \\
\hline & $d_{1}( \pm 1 \AA ̊)$ & $d_{2}$ & $\begin{array}{l}\rho_{1} \\
( \pm 0.05 \\
\mathbf{x} 10^{-6} \\
\left.\AA^{-2}\right)\end{array}$ & $\rho 2$ & $\Delta \rho$ & $\begin{array}{l}N \\
( \pm 5)\end{array}$ & $\Delta \mathrm{Q} / \mathrm{Q}$ & & & & & \\
\hline 0.6 & 21 & 17 & 3.96 & 2.40 & 1.56 & 30 & 0.12 & & & & & \\
\hline
\end{tabular}

A more complete summary of the key model parameters at the different $\mathrm{CaCl}_{2}$ concentrations are summarised in table S2 in the Supporting Information. The key model parameters presented here are similar to those reported for $\mathrm{MES} / \mathrm{AlCl}_{3}$ in the absence of $\mathrm{CaCl}_{2}$, see table 1 in reference 19.

The neutron reflectivity data from a monolayer and for structures up to and including 3 bilayers are modelled using the exact optical matrix methods (26), and in the examples shown in figure $2 \mathrm{~b}$, table 1 and table S2 in the Supporting Information a discreet number of layers, 1, 3, or 6, are used to model the $\mathrm{S}_{0}, \mathrm{~S}_{1}$ and $\mathrm{S}_{2}$ structures. For the neutron reflectivity data which is characterised by a single Bragg peak a different approach is more convenient and a surface multilayer model based on the kinematic approximation $(41,42)$ is used. This approach has been extensively applied to a range of similar systems, and the key model parameters are the bilayer thickness, $\mathrm{d}_{\mathrm{t}}$ (where $\mathrm{d}_{\mathrm{t}}=\mathrm{d}_{1}+\mathrm{d}_{2}$ and $\mathrm{d}_{1}, \mathrm{~d}_{2}$ are the hydrophobic alkyl chain and hydrated hydrophilic regions of the bilayer, $\rho_{1}$ and $\rho_{2}$ are their respective scattering length densities, and $\left.\Delta \rho=\rho_{1}-\rho_{2}\right) . \mathrm{N}$ is the number of bilayers, and $\Delta \mathrm{Q} / \mathrm{Q}$ a resolution term. The visibility, relative reflectivity, of the Bragg peak is directly related to $\mathrm{N}$ and $\Delta \rho$; and these are partially correlated. However $\Delta \rho$ also largely determines the reflectivity in the $\mathrm{Q}$ region below the Bragg peak. The width of the Bragg peak is related to $1 / \mathrm{N}$. The lack of subsidiary interference fringes below the Bragg peak imply that the extent of the multilayer structure is relatively large, $\mathrm{N}$ is large. However the reflectivity is convoluted with $\Delta \mathrm{Q} / \mathrm{Q}$, the instrumental resolution, which is 
typically $\sim 0.05$. However a larger value, $\sim 0.12$, is required to reproduce the data. This is attributable to surface disorder in the form of lamellar crystallites at the surface, which further broaden the $\Delta \mathrm{Q} / \mathrm{Q}$ value and can be likened to a surface mosaic spread. This is also reinforced by the $\rho_{1}$ and $\rho_{2}$ values, and hence $\Delta \rho$, which also imply a degree of lateral and orthogonal disorder. This manifests itself in the model as a decrease in $\Delta \rho$ due to apparent overlap between the deuterium labelled alkyl chain and hydrated headgroup regions of the bilayer structure. In contrast the model parameters for the single and double bilayer structures ( $\mathrm{S}_{1}$ and $\mathrm{S}_{2}$ structures), where the scattering length density of the nominally hydrated headgroup regions in the structure are smaller, imply a greater degree of order and coverage.

\section{(ii) $1 \mathrm{mM} \mathrm{MES} / \mathrm{AlCl}_{3} / \mathrm{MgCl}_{2}$}

To further explore the role of the competitive adsorption of different counterions neutron reflectivity measurements were also made for $1 \mathrm{mM} \mathrm{MES} \mathrm{in} \mathrm{MgCl}_{2}$, for $\mathrm{MgCl}_{2}$ concentrations from 2 to $25 \mathrm{mM}$, and at fixed $\mathrm{MgCl}_{2}$ concentrations of 5,10 and $25 \mathrm{mM}$ and $\mathrm{AlCl}_{3}$ concentrations in the range 0.02 to $1 \mathrm{mM}$.

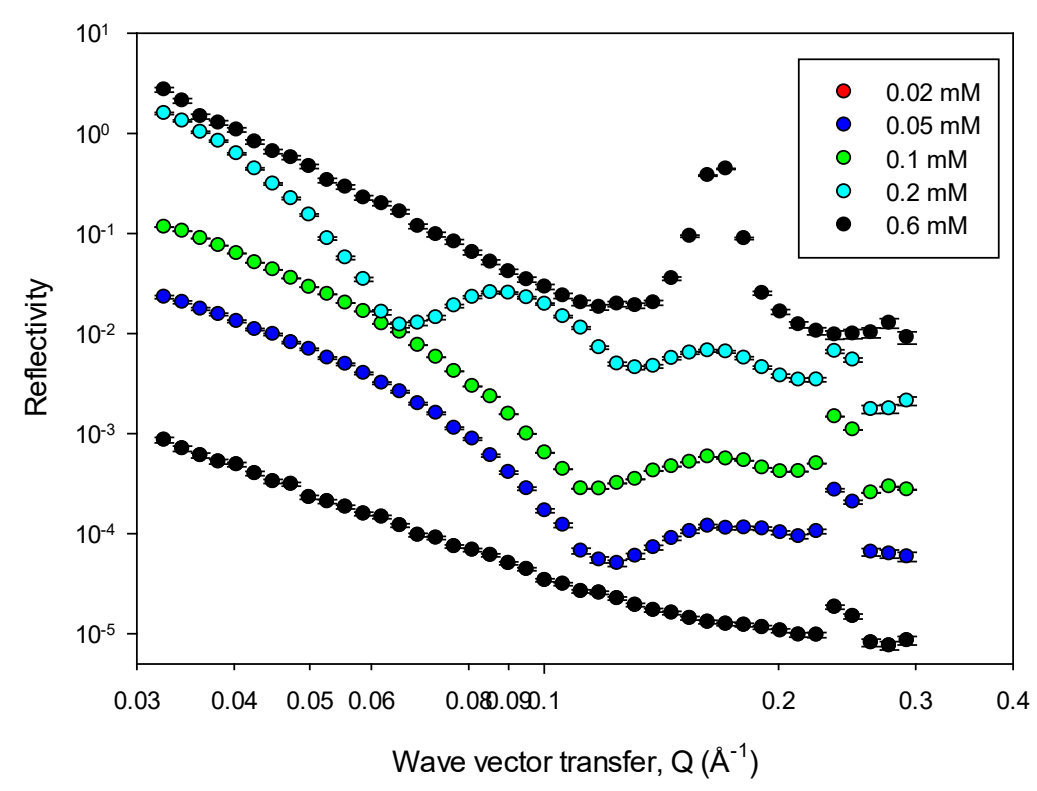

Figure 4. Neutron reflectivity for $1 \mathrm{mM} M E S$ in $5 \mathrm{mM} \mathrm{MgCl}_{2}$, and $0.02,0.05,0.1,0.2$ and 0.6 $\mathrm{mM} \mathrm{AlCl}_{3}$; see legends for details. Each curve, from bottom to top are shifted vertically by x16 for 0.05, 0.1 mM data and x64 for 0.2, $0.6 \mathrm{mM}$ data, with respect to the previous curve.

With the addition of $\mathrm{MgCl}_{2}$, in the absence of $\mathrm{AlCl}_{3}$ the adsorbed layer, in 2 to $10 \mathrm{mM} \mathrm{MgCl}_{2}$, is a monolayer with a thickness $\sim 20 \pm 2 \AA$ and an area / molecule $\sim 47 \AA^{2}$, and an adsorbed amount of $3.63 \times 10^{-10} \mathrm{~mol} \mathrm{~cm}^{-2}$. This is a value slightly less than the adsorbed amounts reported earlier 
in $\mathrm{NaCl}$ and $\mathrm{CaCl}_{2}$. At higher $\mathrm{MgCl}_{2}$ concentrations, $25 \mathrm{mM}$, both in the presence and absence of $\mathrm{AlCl}_{3}$ the reflectivity data are unreliable due to precipitation effects, which do not occur in these concentration ranges in the presence of $\mathrm{AlCl}_{3}$ and $\mathrm{AlCl}_{3} / \mathrm{CaCl}_{2}$ mixtures.

In the presence of $\mathrm{MgCl}_{2}$ and at variable $\mathrm{AlCl}_{3}$ concentrations a broadly similar evolution in the surface structure to that shown for $\mathrm{AlCl}_{3}$ and $\mathrm{AlCl}_{3} / \mathrm{CaCl}_{2}$ mixtures (see figure 2) occurs. With the addition of $\mathrm{MgCl}_{2}$ the evolution in the surface structure from $\mathrm{S}_{0}$ to $\mathrm{S}_{1}$ to $\mathrm{S}_{2}$ to $\mathrm{S}_{\mathrm{n}}$ occurs at increasingly higher $\mathrm{AlCl}_{3}$ concentrations. That is, the major features, Bragg peak, and interference fringes, occur at identical Q values for each mixture, but the visibility / definition of the features vary. The evolution in the reflectivity with increasing $\mathrm{AlCl}_{3}$ concentration for 1 $\mathrm{mM}$ MES / $5 \mathrm{mM} \mathrm{MgCl}$. is shown in figure 4.

The notable difference between the data in figure 4 and in figure 2 is that at the lower $\mathrm{AlCl}_{3}$ concentrations, 0.02 to $0.2 \mathrm{mM}$, there is a small additional Bragg peak visible at a high Q value. This is not present at the highest $\mathrm{AlCl}_{3}$ concentration studied, $0.6 \mathrm{mM}$, as illustrated in figure 5b. The major Bragg peak that occurs at high $\mathrm{Q}$ values for high $\mathrm{AlCl}_{3}$ concentrations is at a $\mathrm{Q} \sim 0.16 \AA^{-1}$, corresponding to a $\mathrm{d}$ spacing $\sim 38 \AA$. The smaller additional Bragg peak observed in the $\mathrm{AlCl}_{3} / \mathrm{MgCl}_{2}$ mixtures occurs at a $\mathrm{Q}$ value $\sim 0.24 \AA^{-1}$ and a d spacing $\sim 26 \AA$. The $d$ spacing and structural parameters of the concentrated lamellar phase that forms at the surface implies a degree of inter-digitation. However the much smaller $d$ spacing of the additional Bragg peak present in the presence of $\mathrm{MgCl}_{2}$ implies a high degree of overlap or inter-digitation between the two halves of the bilayer and a very closed packed structure. The occurrence of the additional Bragg peak and its $d$ spacing implies an additional surface phase. However the relatively low reflectivity or visibility of the Bragg peak implies a relatively low coverage compared to the predominant surface structure present.

The approximate surface phase diagram for $1 \mathrm{mM}$ MES with $\mathrm{AlCl}_{3}$ and at fixed $\mathrm{MgCl}_{2}$ concentrations of 5 and $10 \mathrm{mM}$ are shown in figure 5 . 


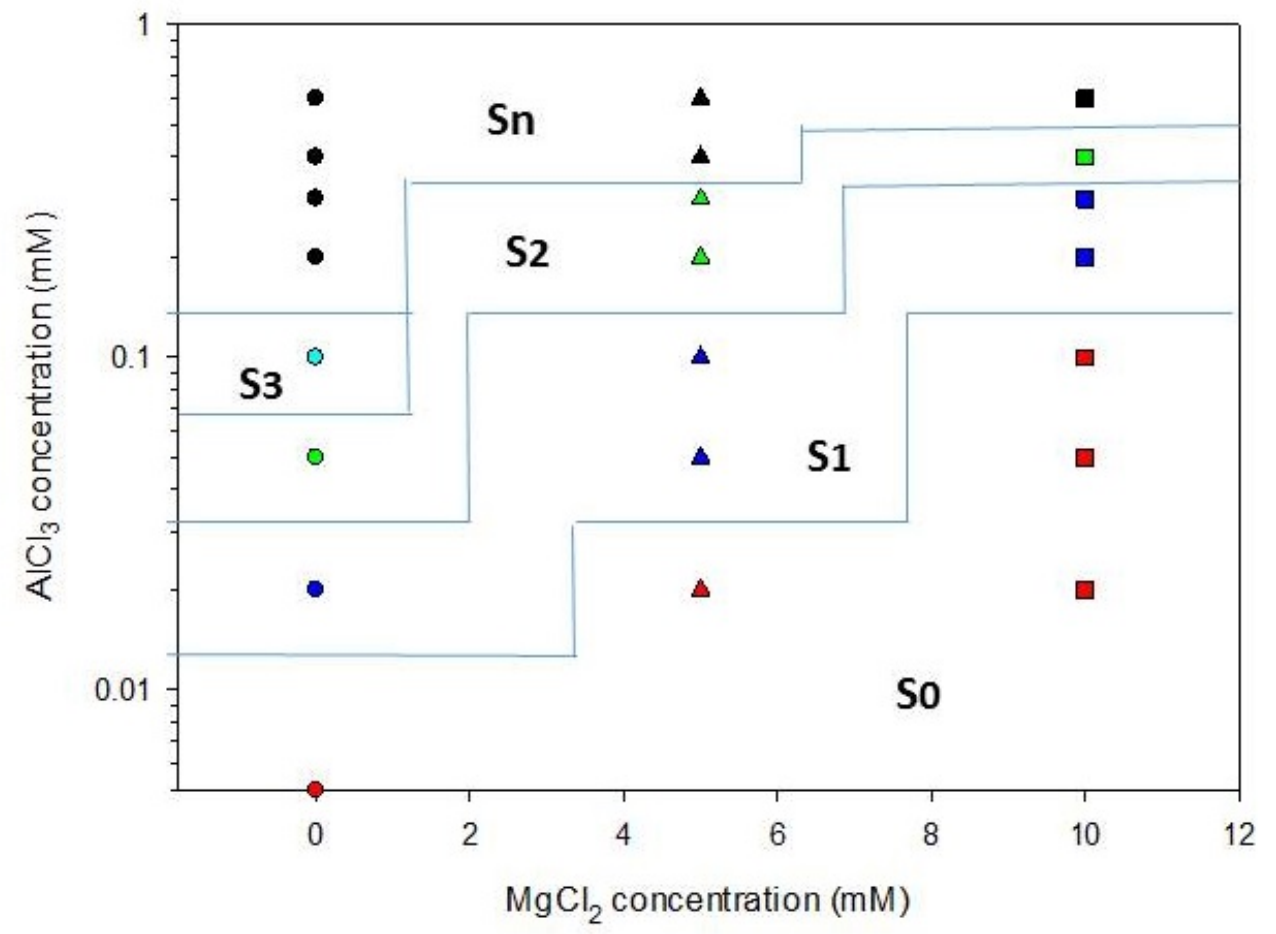

FIGURE 5. Approximate surface phase diagram for $1 \mathrm{mM} \mathrm{MES} \mathrm{/} \mathrm{AlCl}_{3} / \mathrm{MgCl}_{2}$; see figure for details. The different data points represent measurements at $0.0 \mathrm{MgCl}_{2}(\bullet), 5 \mathrm{mM} \mathrm{MgCl}_{2}(\mathbf{\Delta})$, and $10 \mathrm{mM} \mathrm{MgCl}_{2}(\mathbf{\square})$; and (red) $S_{0}$ monolayer,(blue) $S_{1}$ monolayer + bilayer, (green) $S_{2} 2$ bilayers, (cyan) $S_{3} 3$ bilayers, and (black) $S_{n}$ multilayers

\section{DISCUSSION}

In general the addition of multivalent counterions causes anionic surfactants to precipitate (29, 30). However the modified headgroup structures of LAS, SLES and MES make them more tolerant to precipitation $(1,2)$. However for these anionic surfactants it has now been extensively demonstrated that surface adsorption, more complex and extensive than monolayer adsorption, and surface multilayer formation, occurs in the presence of multivalent counterions $(18,19,21-25)$ at low surfactant and counterion concentrations. The attractive force required to promote the concentrated multilayer formation at the interface from dilute solutions arises from the strong binding of the divalent or trivalent counterions within the plane, and through bridging across adjacent layers. For LAS (LAS-6 di-chain isomer) the addition of $\mathrm{Ca}^{2+}$ is sufficient to promote surface multilayer formation. Whereas for SLES and MES the addition of a trivalent counterion, $\mathrm{Al}^{3+}$, is required $(18,19,22-25)$. For LAS (21) and SLES it was 
further shown that the bulky headgroup of a non-ionic cosurfactant disrupts the counterion binding which drives the multilayer formation. It was also shown (25) for SLES how varying the trivalent counterion from $\mathrm{Al}^{3+}$ to $\mathrm{Cr}^{3+}$ had important consequences, which were associated with the nature of the counterion, it's hydrated radius and the strength of binding. The addition of $\mathrm{Cr}^{3+}$ instead of $\mathrm{Al}^{3+}$ partially supresses the evolution of the hierarchy of surface structures encountered. This was attributed to a greater reluctance for exchange with the primary hydration shell for $\mathrm{Cr}^{2+}$, resulting in a shielding of the electrostatic interaction and a reduced surfactant-counterion binding.

Although the addition of $\mathrm{Ca}^{2+}$ and $\mathrm{Mg}^{2+}$ to MES reduces the area / molecule in monolayer adsorption to a value comparable to the effect of $\mathrm{Al}^{3+}$ where monolayer adsorption still occurs, it is not sufficient in the single chain surfactants to promote surface multilayer formation. This strongly implies that the additional bridging across layers is an important factor in producing the attractive force required in these systems.

The addition of $\mathrm{Ca}^{2+}$ in the presence of $\mathrm{Al}^{3+}$ shifts the evolution of the surface multilayer structures, see figure 3 , to progressively higher $\mathrm{Al}^{3+}$ concentrations, and is indicative that the competitive adsorption of $\mathrm{Ca}^{2+}$ in the presence of $\mathrm{Al}^{3+}$ to the surface and the micellar phase is responsible. This is broadly similar to that reported by Maneedaeng et al (32) and Stellner et al (33), who showed that the addition of $\mathrm{NaCl}$ progressively shifted the onset of precipitation to higher $\mathrm{Ca}^{2+}$ concentrations for SDS, sodium dodecyl sulfate, due to the competition between $\mathrm{Na}^{+}$and $\mathrm{Ca}^{2+}$ to micelles and the surface. In particular, Maneedaeng et al (32), from emf measurements and the application of the Corrins-Harkins equation to $\mathrm{cmc}$ data, showed that although the degree of counterion binding to SDS micelles was constant, $\sim 0.65$, for concentrations much greater than the $\mathrm{cmc}$, as the SDS concentration increased the amount of $\mathrm{Ca}^{2+}$ binding decreases and the amount of $\mathrm{Na}^{+}$binding increases. Alargova et al (37-39) developed a thermodynamic model to account for the surface tension data and micellar growth of SLES in the presence of $\mathrm{Al}^{3+}$ counterions based on the competitive adsorption between $\mathrm{Al}^{3+}$ and $\mathrm{Na}^{+}$, and which provided an estimate of the greater binding energy of $\mathrm{Al}^{3+}$ compared to $\mathrm{Na}^{+}$. Furthermore they showed that due to the different binding efficiencies $\mathrm{Ca}^{2+}$ was less effective at promoting micellar growth than $\mathrm{Al}^{3+}$.

The addition of $\mathrm{Mg}^{2+}$ in the presence of $\mathrm{Al}^{3+}$ produced a broadly similar shift in the evolution of the surface multilayer structures, see figure 5. However there are three important differences. Firstly in the presence and absence of $\mathrm{Al}^{3+}, \mathrm{Mg}^{2+}$ promotes the precipitation of MES at $\mathrm{Mg}^{2+}$ 
concentrations $\geq 25 \mathrm{mM}$. This is not observed for $\mathrm{Ca}^{2+}$ in that concentration range. In the region of monolayer adsorption the addition of $\mathrm{Mg}^{2+}$ results in a slightly lower adsorption compared to that for an equivalent amount of $\mathrm{Ca}^{2+}$. Alargova et al (39) observed that $\mathrm{Mg}^{2+}$ was less effective at promoting micellar growth than $\mathrm{Ca}^{2+}$. Both the changes in adsorption and the observations of Alargova et al (39) imply that $\mathrm{Mg}^{2+}$ is less strongly bound than $\mathrm{Ca}^{2+}$, and this is associated by Alargova et al with the stronger hydration of $\mathrm{Mg}^{2+}$ than $\mathrm{Ca}^{2+}$. The observations of the effect of $\mathrm{Cr}^{3+}$ compared to $\mathrm{Al}^{3+}$ on the surface ordering of SLES (25) where the surface ordering is less pronounced, is also an indication of the importance of the strength of the hydration of the counterion.

The other two major differences between $\mathrm{Ca}^{2+}$ and $\mathrm{Mg}^{2+}$ relate to precipitation. Despite the observations of Alargova et al (39) the addition of $\mathrm{Mg}^{2+}$ to MES is more effective at driving the system towards precipitation than $\mathrm{Ca}^{2+}$; and this has in this study limited the range of $\mathrm{Mg}^{2+}$ concentrations explored compared to $\mathrm{Ca}^{2+}$, as discussed earlier. However, this is in contrast to the observations of Stellner et al (33) who report a lower Krafft temperature for $\operatorname{Mg}(\mathrm{DS})_{2}$ that for $\mathrm{Ca}(\mathrm{DS})_{2}$ (where DS refers to dodecyl sulfate), which implies a greater tolerance to precipitation in $\mathrm{Mg}^{2+}$ than $\mathrm{Ca}^{2+}$. However this may well be due to specific binding effects associated with the different headgroup geometries of the dodecyl sulfate and MES surfactants.

Finally, as presented earlier in figure 4, an additional Bragg peak is present in the reflectivity data at high $\mathrm{Q}$ values. This corresponds to a d spacing $\sim 26 \AA$, compared to the $\mathrm{d}$ spacing $\sim 38$ $\AA$ associated with the main Bragg peak observed at a Q value $\sim 0.16 \AA^{-1}$. This occurs at $\mathrm{MgCl}_{2}$ concentrations of 5 and $10 \mathrm{mM}$ and for $\mathrm{AlCl}_{3}$ concentrations up to the point where the $\mathrm{S}_{\mathrm{n}}$ surface phase (associated with the Bragg peak at $\mathrm{Q} \sim 0.16 \AA^{-1}$ ) appears. This is attributed to an additional $S_{n}$ surface phase which is more condensed and which coadsorbs with the other layered surface structures. It has a relatively low coverage compared to the other coexisting phases. It is associated with the stabilisation of a compact component at the surface prior to precipitation, and the closer proximity of precipitation in the presence of $\mathrm{Mg}^{2+}$.

\section{CONCLUSIONS}

Neutron reflectivity has been used to explore the impact of competitive adsorption of the divalent counterions $\mathrm{Ca}^{2+}$ and $\mathrm{Mg}^{2+}$ with the trivalent $\mathrm{Al}^{3+}$ counterion on the adsorption of the anionic surfactant MES at the air-water interface. The neutron reflectivity data show that, although $\mathrm{Ca}^{2+}$ and $\mathrm{Mg}^{2+}$ alone result only in monolayer adsorption, mixtures of $\mathrm{Ca}^{2+} / \mathrm{Al}^{3+}$ and $\mathrm{Mg}^{2+} / \mathrm{Al}^{3+}$ result in surface ordering in the form of a range of surface multilayer structures. 
These structures, as previously reported for MES $(19,20)$ and SLES (22-25), evolve as the $\mathrm{AlCl}_{3}$ concentration increases. The addition of $\mathrm{CaCl}_{2}$ or $\mathrm{MgCl}_{2}$ progressively shifts the structural pattern observed to higher $\mathrm{AlCl}_{3}$ concentrations; due to the competitive adsorption of $\mathrm{Al}^{3+}$ and the divalent ions for the surface and micelles. This competitive counterion adsorption is broadly similar to that responsible for the reduced precipitation of anionic surfactants by $\mathrm{AlCl}_{3}$ in the presence of $\mathrm{NaCl}(32,33)$. Specific ion binding effects were attributed to the partial coadsorpiton of a more compact lamellar structure in the presence of $\mathrm{MgCl}_{2}$, broadly related to that discussed by Alargova et al (39) in the context of micellar growth and by $\mathrm{Xu}$ et al (25) regarding surface multilayer formation. Finally the addition of mixed counterions to anionic surfactants provides a facile route to manipulating and in some cases delaying the formation of the surface structures that are observed in anionic surfactant / multivalent counterion mixtures.

\section{ACKNOWLEDGEMENTS}

The provision of beam time on the INTER reflectometer at ISIS is acknowledged. The invaluable scientific and technical input and support from the staff at ISIS is greatly appreciated.

\section{SUPPORTING INFORMATION}

Additional tables are included in the Supporting Information 


\section{REFERENCES}

(1) J. J. Scheibel, The evolution of anionic surfactant technology to meet the requirements of the laundry detergent industry, J. Surf. Det. 2004, 7, 319-328

(2) Y U Yangxin, Z Jin, A E Bayley, Development of surfactants and builders in detergent formulations, Chinese J. Chem. Eng. 2008, 16, 517-527

(3) I Johansson, M Svensson, Surfactants based on fatty acids and other natural hydrophobes, Curr. Opin. Coll. Int. Sci. 2001, 6, 178-188

(4) Z A Maurad, R Ghazali, P Siwayanan, Z Ismail, S Ahmad, $\alpha$-sulfonated methyl esters as an active ingredient in palm-based powder detergents, J. Surf. Det. 2006, 9, 161-167

(5) D Martinez, G Orozoco, S Rincon, I Gil, Simulation and pre-feasibility analysis of the production process of $\alpha$-methyl ester sulfonates, Bioresource Technol. 2010, 101, 87628771

(6) S Ahmad, P Siwayanan, H A Murad, H A Aziz, H Seng Soi, Beyond biodiesel, methyl esters as a route for the production of surfactant feedstocks, Inform, 2007, 18, 216-228

(7) L Cohen, F Soto, M S Imura, Separation and extraction of $\phi$ methyl ester sulfonates: new features, J. Surf. Det. 2001, 4, 73-74

(8) W Stein, H Haumann, $\alpha$-sulfonated fatty acids and esters: manufacturing, process, properties and applications, JAOCS, 1975, 52, 323-329

(9) L Cohen, F Trujillo, Synthesis, characterisation and surface properties of sulfonated methyl esters, J. Surf. Det. 1998, 1, 338-341

(10) K Ohbu, M Fujiwara, Y Abu, Physicochemical properties of $\alpha$-sulfonated fatty acid esters, Prog. Coll. Polym. Sci. 1998, 109, 85-92

(11) S P Wong, W H Lim, S F Cheng, C H Chuah, Properties of sodium methyl ester 4-sulfoalkylate / trimethyl ammonium bromide mixtures, J. Surf. Det. 2012, 15, 601611

K D Danov, R D Stanimirova, P A Kralchevsky, E S Basheva, V I Ivanova, J T Petkov, Sulfonated methyl esters of fatty acids in aqueous solution: interfacial and micellar properties, J. Coll. Int. Sci. 2015, 457, 307-318

J Aparicio, B W MacArthur, W B Sheats, B J Brooks, MES-myths, mysteries and perspective on properties and use, ICSD, 2012, Shanghai, PRC

(14) D W Roberts, Aquatic toxicity - are surfactant properties relevant, J. Surf. Det. 2000, 3, 309-315 

aquatic effects on palm-based $\alpha$-sulfonated methyl esters, J. Oil Palm Res. 2006, 18, $225-230$

R Ghazali, A Ahmad, Biodegradability and ecotoxicity of palm stearin based methyl ester sulfonates, J. Oil Palm Res. 2004, 16, 39-44

$\mathrm{R}$ Ghazali, The effect of disalt on the biodegradability of methyl ester sulfonates, MES, J. Oil Palm Res. 2002, 14, 45-50

H Xu, P X Li, K Ma, R Welbourn, J Penfold, D W Roberts, R K Thomas, J T Petkov, Adsorption of methyl ester sulfonate at the air-water interface: can limitations in the application of the Gibbs equation be overcome by 'computer purification', Langmuir, 2017, 33, 9944-9953

H Xu, R K Thomas, J Penfold, P X li, K Ma, R Welbourn, D W Roberts, J T Petkov, The impact of electrolyte on the adsorption of the anionic surfactant methyl ester sulfonate at the air-solution interface: surface multilayer formation, J. Coll. Int. Sci. 2017, 512, 231-238

H Xu, P Li, K Ma, R J L Welbourn, J Penfold, R K Thomas, D W Roberts, J T Petkov, K L Choo, S Y Khoo, Adsorption and self-assembly in methyl ester sulfonate surfactants, their eutectic mixtures and the role of electrolyte, J Coll. Int. Sci., 2018, $516,456-465$

J Penfold, R K Thomas, C C Dong, I Tucker, K Metcalfe, S Golding, I Grillo, Equilibrium surface adsorption behaviour in complex anionic/ non-ionic surfactant mixtures, Langmuir, 2007, 23, 10140-10149

(22) J T Petkov, I M Tucker, J Penfold, R K Thomas, D N Petsev, C C Dong, S Golding, I Grillo, The impact of multivalent counterions $\mathrm{Al}^{3+}$ on the surface adsorption and self-assembly of the anionic alkyloxyethylene sulfate and anionic / non-ionic surfactant mixtures, Langmuir, 2010, 26, 16691-16709

H Xu, J Penfold, R K Thomas, J T Petkov, I Tucker, J R P Webster, The formation of surface multilayers at the air-water interface from sodium polyethylene glycol monoalkyl ether sulfate / $\mathrm{AlCl}_{3}$ solutions: the role of the size of the polyethylene oxide group, Langmuir, 2013, 29, 11656-11666

(24) H Xu, J Penfold, R K Thomas, J T Petkov, I Tucker, J R P Webster, The formation of surface multilayers at the air-water interface from sodium polyethylene glycol monoalkyl ether sulfate / $\mathrm{AlCl}_{3}$ solutions: the role of the alkyl chain length, Langmuir, 2013, 29, 12744-12753 
Terry, Ion specific effects in trivalent counterion induced surface and solution selfassembly of the anionic surfactant, SLES, Langmuir, 2014, 30, 4694-4707

J R Lu, R K Thomas, J Penfold, Surfactant layers at the air-water interface: structure and composition, Adv. Coll. Int. Sci. 2000, 84, 143-304

N M Va Os, J R Haak, L A M Rupert, Physico-chemical properties of selected anionic, cationic and non-ionic surfactants, Elsevier, Amsterdam, 1993 counterions on the sphere to rod transition, J. Phys. Chem. 1989, 93, 8354-8366

(29) B L Chou, J H Bae, Surfactant precipitation and redissolution in brine, J. Coll. Int. Sci. 1983, 96, 192-203

P Somasundaran, K P Ananthapadmanabhan, M S Celik, Precipitation redissolution phenomena in sulfonate $-\mathrm{AlCl}_{3}$ solutions, Langmuir, 1988, 4, 1061-1063 on the flocculation of Lauryl sulfate micelles by $\mathrm{Al}^{3+}$, Langmuir, 2002, 18, 8295-8301

A Maneedaeng, K J Haller, B P Grady, A E Flood, Thermodynamic parameters and counterion binding to the micelle in binary anionic surfactants, J. Coll. Int. Sci. 2011, 356, 598-604

K L Steller, J F Scamehorn, Surfactant precipitation in aqueous solutions containing mixtures of anionic and non-ionic surfactants, J. Am. Oil Chem. Soc. 1986, $63,566-574$

(34) P Paton-Morales, F I Talens-Alesson, Effect of ionic strength and competitive adsorption of $\mathrm{Na}^{+}$on the flocculation of Lauryl sulfate micelles with $\mathrm{Al}^{3+}$, Langmuir, 2001, 17, 6059-6064

K Hac-Wydo, I Palasinska, P Miskowiec, The comparative studies of the ability of anionic surfactants to bind lead (II) ions, J. Mol. Liq., 2016, 219, 1071-1077

V E Haverd, G C Warr, Cation selectivity at the air / anionic surfactant solution interface, Langmuir, 2000, 16, 157-160

R G Alargova, K D Danov, P A Kralchevsky, G Broze, A Mahreteab, Growth of giant rodlike micelles in ionic surfactants in the presence of $\mathrm{Al}^{3+}$ counterions, Langmuir, 1998, 14, 4036-4049

R G Alargova, V P Ivanova, P A Kralchevsky, A Mahreteab, G Broze, Growth of rodlike micelles in anionic surfactant solutions in the presence of $\mathrm{Ca}^{2+}$ counterions, Coll. Surf. A 1998, 142, 201-218 
(39) R G Alargova, J T Petkov, D N Petsev, Micellisation and interfacial properties of alkyloxyethylene sulfate surfactants in the presence of multivalent counterions, J. Coll. Int. Sci., 2003, 261, 1-11

(40) INTER reflectometer at the ISIS Facility, http://www.isis.stfc.ac.uk/instruments/INTER

(41) I M Tidswell, B M Ocko, P S Pershan, S R Wasserman, G M Whitesides, J D Axe, X-ray specular reflection studies on silicon coated by organic monolayers (alkylsiloxanes), Phys Rev B, 1990, 41, 1111-1128

(42) S K Sinha, M K Sanyal, H Homma, S Szpala, H Gibaud, H Morkov, X-ray scattering studies from surface roughness of GaAs / AlAs multilayers, Physica B, 1994, $198,72-77$

(43) 


\section{SUPPORTING INFORMATION}

Table S1. Key model parameters for $1 \mathrm{mM} \mathrm{MES} \mathrm{/} \mathrm{CaCl}_{2}$

\begin{tabular}{|c|c|c|c|c|}
\hline $\begin{array}{c}\mathrm{CaCl}_{2} \\
\text { concentration } \\
(\mathbf{m M})\end{array}$ & $d\left( \pm 2 \AA^{2}\right)$ & $\begin{array}{c}\rho\left( \pm 0.05 \times 10^{-6}\right. \\
\left.\AA^{-2}\right)\end{array}$ & $A\left( \pm 2 \AA^{2}\right)$ & $\begin{array}{c}\Gamma\left( \pm 0.1 \times 10^{-10}\right. \\
\left.m o l \mathrm{~cm}^{-2}\right)\end{array}$ \\
\hline 5 & 21 & 3.22 & 43 & 3.86 \\
\hline 10 & 21 & 3.29 & 43 & 3.86 \\
\hline 25 & 22 & 3.22 & 43 & 3.86 \\
\hline 50 & 21 & 3.29 & 42 & 3.95 \\
\hline
\end{tabular}

Table S2. Key model parameters from analysis of neutron reflectivity data for $1 \mathrm{mM} M E S$ in $\mathrm{AlCl}_{3} / \mathrm{CaCl}_{2}$ mixtures.

(a) $5 \mathrm{mMCaCl}_{2}$

\begin{tabular}{|c|c|c|c|c|c|c|c|c|c|c|c|c|}
\hline $\begin{array}{l}\mathrm{AlCl}_{3} \\
\text { concentration } \\
(\mathrm{mM})\end{array}$ & $\mathbf{d}_{1}( \pm 1 \AA)$ & $\begin{array}{l}\rho_{1} \\
( \pm 0.05 \\
\mathbf{x} 10^{-6} \\
\left.\AA^{-2}\right)\end{array}$ & $\mathbf{d}_{2}$ & $\mathbf{\rho}_{2}$ & $\mathbf{d}_{3}$ & $\rho_{3}$ & $d_{4}$ & $\rho_{4}$ & $\mathbf{d}_{5}$ & $\rho_{5}$ & $\mathbf{d}_{6}$ & $\rho_{6}$ \\
\hline 0.02 & 21 & 3.22 & - & - & - & - & - & - & - & - & - & - \\
\hline 0.05 & 23 & 3.80 & 9 & 0.87 & 17 & 1.93 & - & - & - & - & - & - \\
\hline 0.10 & 15 & 4.6 & 3 & 1.16 & 32 & 3.17 & & & & & & \\
\hline 0.20 & 27 & 3.53 & 6 & 1.04 & 25 & 4.18 & 8 & 1.38 & 24 & 4.24 & 16 & 0.60 \\
\hline 0.30 & \multicolumn{12}{|c|}{ Double fringe pattern, as for $0.2 \mathrm{mM}$, not analysed } \\
\hline & $d_{1}( \pm 1 \AA ̊)$ & $\mathbf{d}_{2}$ & $\begin{array}{l}\rho_{1} \\
( \pm 0.05 \\
\mathbf{x} 10^{-6} \\
\left.\AA^{-2}\right)\end{array}$ & $\mathbf{\rho}_{2}$ & $\Delta \rho$ & $\begin{array}{l}\text { N } \\
( \pm 5)\end{array}$ & $\Delta \mathbf{Q} / \mathbf{Q}$ & & & & & \\
\hline 0.4 & \multicolumn{7}{|c|}{ Multilayer structure with Bragg Peak, not analysed } & & & & & \\
\hline 0.6 & 21 & 17 & 3.96 & 2.40 & 1.56 & 30 & 0.12 & & & & & \\
\hline
\end{tabular}


(b) $25 \mathrm{mMCaCl}$

\begin{tabular}{|c|c|c|c|c|c|c|c|c|c|c|c|c|}
\hline $\begin{array}{l}\mathrm{AlCl}_{3} \\
\text { concentration } \\
(\mathrm{mM})\end{array}$ & $d_{1}( \pm 1 \AA)$ & $\begin{array}{l}\rho_{1} \\
( \pm 0.05 \\
\times 10^{-6} \\
\left.\AA^{-2}\right)\end{array}$ & $\mathbf{d}_{2}$ & $\boldsymbol{\rho}_{2}$ & $d_{3}$ & $\rho_{3}$ & $d_{4}$ & $\rho_{4}$ & $\mathrm{~d}_{5}$ & $\rho_{5}$ & $d_{6}$ & $\rho_{6}$ \\
\hline 0.02 & 21 & 3.29 & - & - & - & - & - & - & - & - & - & - \\
\hline 0.05 & 20 & 3.36 & 34 & 0.93 & - & - & - & - & - & - & - & - \\
\hline 0.10 & 24 & 2.61 & 7 & 0.68 & 23 & 3.80 & - & - & - & - & - & - \\
\hline 0.20 & 27 & 3.66 & 5 & 1.05 & 20 & 4.10 & - & - & - & - & - & - \\
\hline 0.30 & 20 & 4.00 & 21 & 1.23 & 30 & 3.66 & - & - & - & - & - & - \\
\hline 0.40 & 24 & 4.62 & 8 & 0.94 & 28 & 3.88 & 10 & 1.24 & 13 & 4.10 & 9 & 1.00 \\
\hline 0.60 & 23 & 3.46 & 6 & 1.07 & 24 & 3.96 & 7 & 1.12 & 26 & 4.32 & 16 & 0.83 \\
\hline 1.0 & 24 & 3,10 & 4 & 1.17 & 29 & 3.81 & 7 & 1.20 & 20 & 5.20 & 9 & 2.00 \\
\hline
\end{tabular}

